\title{
SAÚDE NO PRESÍDIO: ANÁLISE DA SAÚDE DOS PRIVADOS DE LIBERDADE
}

\author{
PRISON HEALTH: HEALTH ANALYSIS OF PRISONERS
}

\author{
Arthur de Abrantes Silva ${ }^{1}$ \\ Ankilma do Nascimento Andrade Feitosa \\ Cindy Karina Soares de Oliveira \\ Geane Silva Oliveira \\ Renata Lívia Silva Fonseca Moreira ${ }^{2}$
}

RESUMO: OBJETIVO: Conhecer a situação de saúde dos indivíduos em cumprimento de pena no Brasil. METODOLOGIA: Tratou-se de uma revisão integrativa de literatura. Para seleção da amostragem, foi realizada uma pesquisa pela base de dados BVSalud, com acesso ao BDENF, LILACS e SciELO, além do Google Acadêmico, utilizando os unitermos População Privada de liberdade, detentos e saúde, somando uma população de 354 artigos na primeira plataforma e 143 na segunda. Como critérios de inclusão, têm-se: Artigos que apresentam a temática do estudo, em português, disponibilizados em texto completo, de acesso gratuito, publicados e indexados em periódicos nacionais nos referidos bancos de dados após o ano de 2015. Foram excluídos teses, dissertações, monografias, revistas literárias, artigos que divergiam com a temática após leitura dos seus resumos, artigos que não com resumo indisponível e publicações que se repetiram nas bases de dados. Após utilização desses critérios, 27 artigos do BVSalud e 12 do Google Acadêmico foram lidos seletiva e analiticamente, de onde restaram seis e três artigos, respectivamente. RESULTADOS E DISCUSSÕES: Percebe-se um sucateamento nos presídios com superlotação e deficiência em recursos humanos e materiais que possam garantir a oferta de serviços de saúde eficazes. As políticas e planos, embora existam, não possuem resolutividade pelas péssimas condições a que os presos são expostos. Os profissionais afirmam deficiência no conhecimento das ações destinadas à promoção de saúde. CONCLUSÃO: Observa-se a necessidade de investimento em estrutura física, recursos humanos e materiais, além de capacitação para que se possa oferecer saúde em termos de promoção, proteção e recuperação.

\footnotetext{
${ }^{1}$ Acadêmico do curso de Bacharelado em Enfermagem da Faculdade Santa Maria (FSM), Cajazeiras - PB. Email: arthurabrantes95@gmail.com.

2 Doutora pela Faculdade de Ciências Médicas Santa Casa. Mestre em Enfermagem pela Universidade Federal da Paraíba (2013). Especialista em Saúde Pública pela Faculdade de Ciências Sociais e Aplicadas (2008). Graduada em Enfermagem pela Universidade Federal da Paraíba (2003). Docente da Faculdade Santa Maria.
} 
Descritores: População Privada de liberdade, detentos, saúde.

ABSTRACT: OBJECTIVE: To know the health situation of individuals serving time in Brazil. METHODOLOGY: This was an integrative literature review. In order to select the sample, a survey was carried out using the BVSalud database, with access to BDENF, LILACS and ScieELO and Google Academics, using the descriptors Imprisoned Population, prisoners and health, with a population of 354 articles on the first platform and 143 on the second. Inclusion criteria: Articles presenting the study topic in Portuguese, available in full text, freely accessible, published and indexed in national journals in these databases after the year 2015. Theses, dissertations, monographs, literary magazines, articles that diverged from the theme after reading their abstracts, articles that did not have their abstracts available and repeated publications were excluded. After using these criteria, 27 articles from BVSalud and 12 from Google Academics were read selectively and analytically, selecting six and three articles, respectively. RESULTS AND DISCUSSIONS: Prisons are left aside, presenting overcrowding and deficiency in human and material resources that can guarantee the provision of effective health services. Despite the existing policies and plans, they are not resolvable due to the poor conditions to which prisoners are exposed. The professionals affirm deficiency in the knowledge on actions focused on health promotion. CONCLUSION: It is necessary to invest in physical structure, human and material resources, besides training to offer health in terms of promotion, protection and recovery.

Descriptors: Imprisoned Population; Prisoners; Health. 


\section{INTRODUÇÃO}

O sistema penitenciário do Brasil possui uma evolução histórica iniciada desde 1850 com a criação do complexo Frei Caneca no Rio de Janeiro, anteriormente denominado Casa de Correção da Corte, onde a demanda existente estava ligada a pequenas delinquências difusas nas classes mais pobres (OLIVEIRA, 2007).

Com os avanços em termos de legislação no decorrer dos anos, foram-se instituindo ambientes para receber a população condenada pela justiça pelo cometimento de delitos ou infrações contra as leis do estado (CAPEZ, 2016).

O crescimento desta população gerou também um aumento da incidência de doenças e agravos que, por muitos autores, é resultado da superlotação e de estruturas físicas inadequadas (BARBOSA et al., 2014).

É realidade, no Brasil, uma grave situação no sistema prisional refletida na prática da violência, precariedade do espaço físico e deficiência no atendimento à saúde. Mesmo com a existência de diversos tratados, inclusive internacionais, percebe-se que não existe praticidade e implantação nestes serviços (BRASIL, 2004).

Em meados de 1984, a lei de execuções penais - LEP, $n^{\circ} 7.210$, surge como um diferencial às ações pontuais até então desenvolvidas, pois aponta como dever do Estado a assistência à saúde, conjuntamente à material, jurídica, educacional, social e religiosa (SILVA, 2015).

O comprometimento do direito à saúde, também garantido pela constituição de 1988, passou a tomar grandes proporções na população privada de liberdade. Visando a responder a esta demanda de saúde importante e cumprir os direitos constitucionais, o Ministério da Saúde (MS) instituiu o Plano Nacional de Saúde no Sistema Penitenciário (PNSSP), através da portaria interministerial 1777 de 09 de setembro de 2003, a qual prevê a inclusão da população encarcerada no Sistema 
Único de Saúde, garantindo que o direito à cidadania seja efetivada na perspectiva dos direitos humanos e seguindo os princípios de diretrizes do SUS (BRASIL, 2004).

Após este importante passo, foi possível qualificar todos os estados e o distrito federal, gerando uma representatividade de 271 equipes de saúde no sistema penitenciário, habilitadas em 239 unidades básicas de saúde prisional, em 154 municípios, podendo contar com médico, enfermeiro, odontólogo, psicólogo, assistente social, auxiliar de enfermagem, e auxiliar de consultório dentário (ACD). (BRASIL, 2013).

De acordo com a problemática supracitada, tendo em vista as políticas públicas destinadas ao controle desta situação e percebendo a mesma como um importante problema de saúde pública, questiona-se: Qual a situação de saúde da população privada de liberdade no Brasil? Qual a efetividade das políticas públicas implantadas dentro do sistema penitenciário Brasileiro?

Visando à resolução destes questionamentos e objetivando conhecer a situação de saúde dos indivíduos em cumprimento de pena no Brasil, tendo em vista o conceito mais amplo de saúde, onde não apenas é a ausência de doença, procedeu-se este estudo com análise de artigos científicos anteriormente publicados dentro da temática.

\section{METODOLOGIA}

O estudo tratou-se de uma revisão de literatura do tipo integrativa, a qual consiste em um tipo de estudo científico onde seus resultados são encontrados através de bibliografias já publicadas por outros autores (POLIT, 2004).

Para Souza; Silva; Carvalho (2010), a revisão integrativa de literatura é a forma mais ampla de se elaborar uma revisão, pois permite a inclusão de estudos experimentais e não-experimentais para uma compreensão completa do fenômeno a ser analisado. A vantagem de uma amostragem consistente, juntamente com a multiplicidade de propostas e de pontos de vista, gera um panorama bastante 
compreensível de onde se podem gerar novos dados e informações acerca de um mesmo tema.

Outro ponto positivo deste tipo de estudo é a oportunidade de analisar estudos sobre diferentes metodologias, permitindo aos revisores sintetizar resultados sem ferir a filiação epistemológica dos estudos empíricos incluídos e ainda possibilitando análise de acordo com o enfoque que o autor ache necessário (SOARES, 2014).

A questão norteadora do estudo é: qual a situação atual de saúde da população carcerária no Brasil?

Para iniciar a pesquisa científica, a priori, foram consultados os descritores de ciência da saúde (DECS) como forma de garantir que o tema a ser pesquisado resultaria em um número de bibliografias que permitisse resultados consistentes. Desta forma, os descritores População Privada de liberdade, detentos e saúde mostraram uma gama de possibilidades de pesquisa para que se pudesse alcançar os objetivos propostos.

O levantamento bibliográfico foi realizado pela Internet, por meio da Biblioteca Virtual em Saúde (BVSalud), nas bases de dados LILACS (Literatura LatinoAmericana em Ciências de Saúde), SciELO (Scientific Electronic Library Online) e BDENF, utilizando os descritores outrora mencionados unidos pelo conectivo and, nos quais inicialmente mostraram um número de 354 artigos relacionados. Utilizando os mesmos descritores, também se procedeu pesquisa em banco de dados do Google Acadêmico, o qual inicialmente mostrou 143 resultados.

Os critérios utilizados para a seleção da amostra foram: artigos que apresentavam a temática do estudo, em português, disponibilizados em texto completo, de acesso gratuito, publicados e indexados em periódicos nacionais nos referidos bancos de dados após o ano de 2015. Foram excluídos teses, dissertações, monografias, revistas literárias, artigos que divergiam com a temática após leitura dos seus resumos, artigos que não tivessem seu resumo disponível e publicações que se repetiram nas bases de dados.

Após a seleção por meio dos critérios de inclusão e exclusão, conseguiu-se reduzir o número de bibliografias para 27 indexadas através da BVSalud e 12 pelo Google Acadêmico. 
Com essas 39 publicações, foi realizada leitura seletiva e analítica com intuito de filtrar as publicações que realmente se enquadrassem nos objetivos propostos. Desta forma, contabilizaram-se seis publicações pela BVSalud, estando três indexadas na base de dados LILACS, duas na SciELO e uma na BDENF. Pelo acesso do Google Acadêmico, extraíram-se três publicações, sendo duas da SciELO e uma da Revista Interface Científica, conforme exposto no quadro abaixo.

Quadro 1: Fluxograma Metodológico.
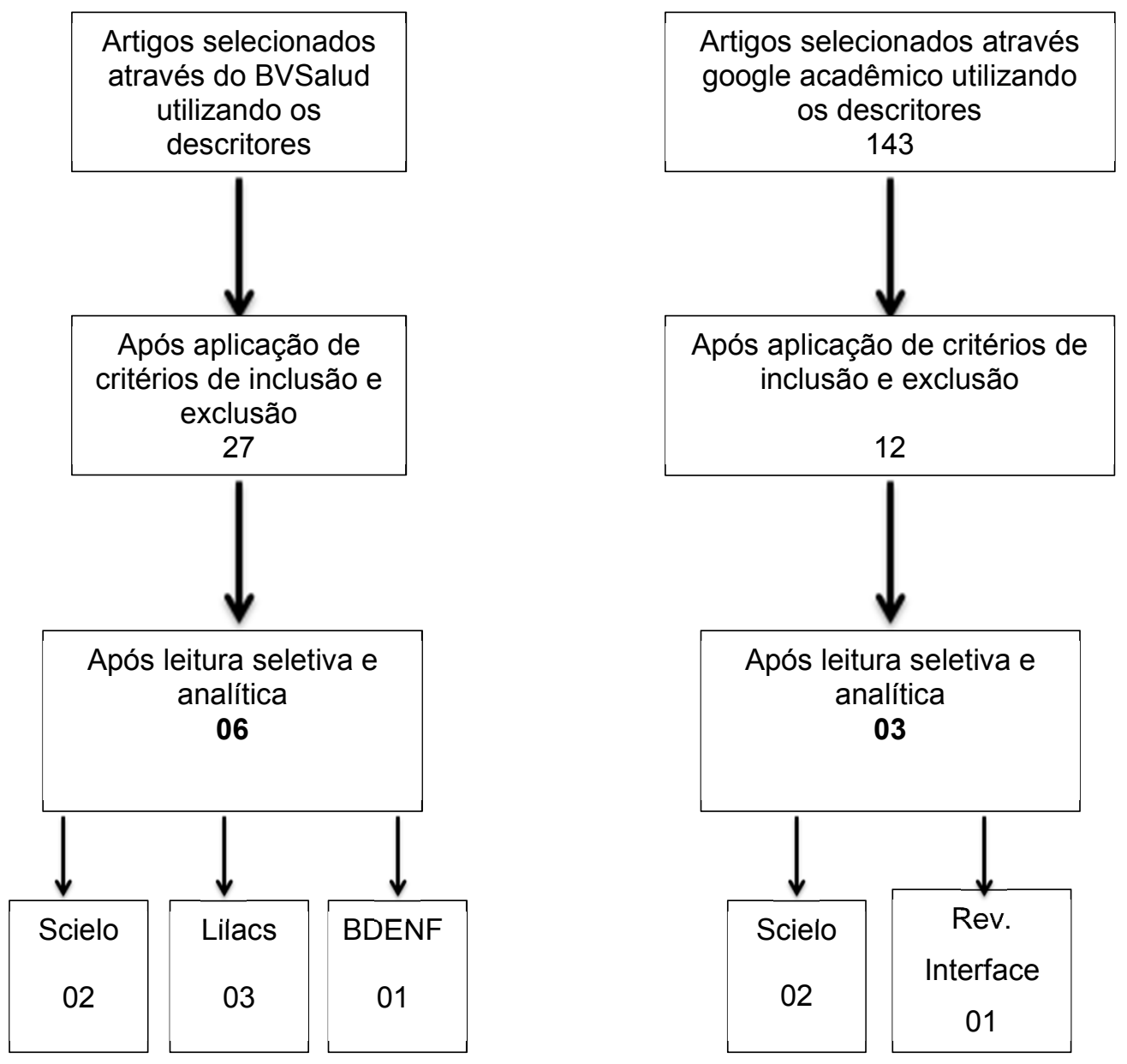

Fonte: Dados da Pesquisa, 2019. 


\section{RESULTADOS E DISCUSSÃO}

Para melhor visualização dos resultados, iniciou-se o processo de discussão categorizando a amostragem como forma de melhor familiarização do leitor com os estudos analisados. $\mathrm{O}$ quadro 2 classifica os artigos de acordo com autor, ano, periódico e tipo e local de estudo.

Quadro 2: Distribuição dos Estudos de acordo com autor, ano, periódico e local de publicação e tipo de estudo.

\begin{tabular}{|c|c|c|c|c|}
\hline Nome do Artigo & Autor/Ano & Periódico & Local & $\begin{array}{l}\text { Tipo de } \\
\text { Estudo }\end{array}$ \\
\hline $\begin{array}{l}\text { 1. O cuidado na atenção } \\
\text { primária à saúde da } \\
\text { população arcerária } \\
\text { masculina no município de } \\
\text { Caraúbas/RN. }\end{array}$ & $\begin{array}{l}\text { HENRIQUE } \\
\text { JUNIOR et al. } \\
\text { (2013) }\end{array}$ & $\begin{array}{l}\text { Rev. } \\
\text { Baiana de } \\
\text { Saúde } \\
\text { Pública }\end{array}$ & $\mathrm{RN}$ & $\begin{array}{l}\text { Descritivo e } \\
\text { exploratório, de } \\
\text { abordagem } \\
\text { qualitativa. }\end{array}$ \\
\hline $\begin{array}{l}\text { 2. Perfil epidemiológicodos } \\
\text { detentos: patologias } \\
\text { notificáveis. }\end{array}$ & $\begin{array}{l}\text { CORDEIRO } \\
\text { E.L et al. } \\
(2018)\end{array}$ & $\begin{array}{l}\text { AV } \\
\text { Enferm }\end{array}$ & PE & $\begin{array}{l}\text { Documental, de } \\
\text { natureza } \\
\text { exploratória e } \\
\text { descritiva, com } \\
\text { abordagem } \\
\text { qualitativa. }\end{array}$ \\
\hline $\begin{array}{l}\text { 3. Atenção à saúde de } \\
\text { pessoas privadas } \\
\text { liberdade. }\end{array}$ & $\begin{array}{l}\text { VALIM, } \\
\text { E.M.A; } \\
\text { DAIBEM, } \\
\text { A.M.L; } \\
\text { HOSSNE, W. } \\
\text { S (2018) } \\
\end{array}$ & Rev. bioét. & MG & $\begin{array}{l}\text { Descritivo e } \\
\text { exploratório, } \\
\text { com } \\
\text { abordagem } \\
\text { qualitativa. }\end{array}$ \\
\hline $\begin{array}{l}\text { 4. Perfil epidemiológico das } \\
\text { pessoas privadas de } \\
\text { liberdade }\end{array}$ & $\begin{array}{l}\text { ALVES, J.P } \\
\text { et al (2017) }\end{array}$ & $\begin{array}{l}\text { Rev } \\
\text { enferm } \\
\text { UFPE on } \\
\text { line } \\
\end{array}$ & PE & $\begin{array}{l}\text { Epidemiológico, } \\
\text { transversal e } \\
\text { descritivo }\end{array}$ \\
\hline $\begin{array}{lr}\text { 5. A saúde dos detentos sob } \\
\text { a responsabilidade das } \\
\text { equipes de saúde da } \\
\text { família: Realidade } \\
\text { Possibilidades. }\end{array}$ & $\begin{array}{l}\text { COSTA, } \\
\text { G.M.C et al. } \\
(2014)\end{array}$ & Rev. APS. & PB & $\begin{array}{l}\text { Descritivo de } \\
\text { natureza } \\
\text { qualitativa }\end{array}$ \\
\hline $\begin{array}{l}\text { 6. Reflexões sobre a } \\
\text { assistência em enfermagem } \\
\text { à mulher encarcerada: Um }\end{array}$ & $\begin{array}{l}\text { SOUSA, G.C; } \\
\text { CABRAL, } \\
\text { K.D.S; }\end{array}$ & $\begin{array}{l}\text { Arq. } \\
\text { Ciênc. } \\
\text { Saúde }\end{array}$ & PR & $\begin{array}{l}\text { Revisão } \\
\text { Integrativa }\end{array}$ \\
\hline
\end{tabular}




\begin{tabular}{|c|c|c|c|c|}
\hline $\begin{array}{lll}\text { estudo de } & \text { revisão } \\
\text { integrativa } & & \\
& & \end{array}$ & $\begin{array}{l}\text { SALGUEIRO- } \\
\text { LEITE, C.D.B } \\
\text { (2018) }\end{array}$ & UNIPAR & & \\
\hline $\begin{array}{l}7 . \quad \text { Demografia, } \\
\text { vulnerabilidades e direito à } \\
\text { saúde da população } \\
\text { prisional brasileira }\end{array}$ & $\begin{array}{l}\text { SOARES } \\
\text { FILHO, } \\
\text { M.M.S; } \\
\text { BUENO, } \\
\text { P.M.M.G } \\
(2016) \\
\end{array}$ & $\begin{array}{l}\text { CiênciA\& } \\
\text { Saúde } \\
\text { Coletiva }\end{array}$ & DF & $\begin{array}{l}\text { Revisão } \\
\text { Literatura }\end{array}$ \\
\hline $\begin{array}{l}\text { 8. O contraditório direito à } \\
\text { saúde de pessoas em } \\
\text { privação de liberdade: o } \\
\text { caso de uma unidade } \\
\text { prisional de Minas Gerais }\end{array}$ & $\begin{array}{l}\text { MARTINS, } \\
\text { E.L.C et al } \\
(2014)\end{array}$ & $\begin{array}{l}\text { Saúde } \\
\text { Soc. }\end{array}$ & MG & $\begin{array}{l}\text { Descritivo } \\
\text { natureza } \\
\text { qualitativa }\end{array}$ \\
\hline $\begin{array}{l}\text { 9. Ocorrência de } \\
\text { infectocontagiosas } \\
\text { pessoas pras } \\
\text { liberdade nadas de } \\
\text { prisional. }\end{array}$ & $\begin{array}{l}\text { SANTOS, R. } \\
\text { Pet al. (2019) }\end{array}$ & $\begin{array}{l}\text { Interfaces } \\
\text { Científicas } \\
\text { - Saúde e } \\
\text { Ambiente }\end{array}$ & SE & $\begin{array}{l}\text { Descritivo, } \\
\text { transversal com } \\
\text { abordagem } \\
\text { quantitativa }\end{array}$ \\
\hline
\end{tabular}

Fonte: Dados da Pesquisa, 2019.

A amostragem utilizada foi composta por nove artigos científicos, indexados em bases de dados confiáveis e periódicos de renome da área de saúde. A ordem de exposição obedeceu à cronologia a qual os mesmos foram encontrados em meio online.

Deu-se prioridade a artigos mais recentemente publicados devido à necessidade de se obter informações novas, tendo em vista a constante mudança em termos de indicadores e percentuais no sistema prisional, fato este justificado pelo crescimento em números de $111 \%$ entre os anos de 2004 e 2014 (LERMEN, 2015). A bibliografia mais antiga data o ano de 2013 , sendo a mais recente do ano de 2019.

Os periódicos utilizados caracterizam-se por revistas científicas da área da saúde, sendo duas delas destinadas à enfermagem e as demais abrangendo toda a área de ciências da saúde.

O local onde o estudo foi realizado reflete bastante a realidade local. A amostragem aparece distribuída pelas regiões Nordeste (RN, PE, SE), Sudeste (MG), Sul (PR) e o Distrito Federal, sendo o nordeste representado pela maioria das publicações analisadas, somando 55\% (5) das bibliografias. Apenas a região centrooeste não aparece nos estudos listados. 
O tipo de estudo predominante é o exploratório descritivo com abordagem qualitativa (55\%), também existindo representação de estudos transversais, revisão de literatura e revisão integrativa. A diversidade de modelos de pesquisa é uma grande vantagem para as revisões integrativas de literatura por propiciar uma melhor interpretação dos resultados (SOUZA; SILVA; CARVALHO, 2010).

$O$ quadro 3 distribui a amostragem quanto aos objetivos e os resultados encontrados pelos autores, a posterior, a discussão agrega também outros estudos conforme concordância ou divergência encontrada pelos revisores.

Quadro 3: Distribuição da amostra conforme os objetivos e resultados.

\begin{tabular}{|c|c|c|}
\hline R/ANO & OBJETIVOS & RESULTADOS \\
\hline $\begin{array}{l}\text { 1. HENRIQUE } \\
\text { JUNIOR et al. } \\
\text { (2013) }\end{array}$ & $\begin{array}{lr}\text { Analisar } & \text { a } \\
\text { efetividade } & \text { do } \\
\text { PNSSP junto à } & \text { apulação carcerária } \\
\text { popula } & \text { masculina, em nível } \\
\text { da atenção primária } \\
\text { à saúderr no } \\
\text { município r de } \\
\text { Caraúbas, Rio } \\
\text { Grande do Norte. } \\
\end{array}$ & $\begin{array}{l}\text { Percebe-se uma deficiência de } \\
\text { conhecimento sobre os deveres do estado } \\
\text { quanto à garantia do direito à saúde dos } \\
\text { apenados, estando esta ligada apenas a } \\
\text { ações curativistas. As barreiras que } \\
\text { impedem o cuidado são o medo, falta de } \\
\text { conhecimento e aceitação e falta de } \\
\text { qualificação profissional. A precariedade } \\
\text { do serviço prestado é consenso entre os } \\
\text { entrevistados. }\end{array}$ \\
\hline $\begin{array}{l}\text { 2.CORDEIRO } \\
\text { E.L et al. } \\
(2018)\end{array}$ & $\begin{array}{l}\text { Perfil epidemiológico } \\
\text { dos } \\
\text { detentos:Patologias } \\
\text { notificáveis. }\end{array}$ & $\begin{array}{l}\text { Percebeu-se uma sub notificação das } \\
\text { patologias que acometem os detentos e } \\
\text { uma prevalência maior de HIV e } \\
\text { tuberculose. As péssimas condições e o } \\
\text { aglomerado de pessoas são fatores que } \\
\text { favorecem ao aparecimento de patologias } \\
\text { e a deficiência no controle do tratamento é } \\
\text { atribuída à deficiência de profissionais de } \\
\text { saúde no serviço. }\end{array}$ \\
\hline $\begin{array}{l}\text { 3.VALIM, } \\
\text { E.M.A; } \\
\text { DAIBEM, } \\
\text { A.M.L; } \\
\text { HOSSNE, W. } \\
\text { S. (2018) }\end{array}$ & $\begin{array}{l}\text { Verificar a realização } \\
\text { de consulta e } \\
\text { orientação sobre } \\
\text { serviço de saúde no } \\
\text { momento } r \text { do } \\
\text { ingresso em uma } \\
\text { penitenciária de } \\
\text { Minas Gerais, Brasil. }\end{array}$ & $\begin{array}{l}\text { Verificou-se ausência de consulta no } \\
\text { ingresso, inexistência de orientação sobre } \\
\text { funcionamento da unidade de saúde } \\
\text { prisional, bem como situações nas quais } \\
\text { são encaminhadas para atendimento } \\
\text { extramuros. Ainda foram relatadas } \\
\text { dificuldade para atendimento, insatisfação } \\
\text { com conduta terapêutica e preocupação } \\
\text { com transmissão intrainstitucional de } \\
\text { doenças. }\end{array}$ \\
\hline & $\begin{array}{lr}\text { Descrever o } & \text { perfil } \\
\text { epidemiológico } & \text { de }\end{array}$ & $\begin{array}{l}\text { Foi observada a prevalência de } \\
\text { hipertensão arterial, transtorno mental e }\end{array}$ \\
\hline
\end{tabular}




\begin{tabular}{|c|c|c|}
\hline & $\begin{array}{l}\text { pessoas privadas de } \\
\text { liberdade. }\end{array}$ & $\begin{array}{l}\text { psiquiátrico e doenças gastrointestinais, } \\
\text { além de uso de drogas lícitas e ilícitas. }\end{array}$ \\
\hline $\begin{array}{l}\text { 5.COSTA, } \\
\text { G.M.C et al. } \\
(2014)\end{array}$ & $\begin{array}{l}\text { Descrever as ações } \\
\text { de saúde realizadas } \\
\text { para os presidiários } \\
\text { e compreender a } \\
\text { organização, } \\
\text { planejamento e } \\
\text { execução desses } \\
\text { serviços pelas } \\
\text { equipes de saúde da } \\
\text { família. }\end{array}$ & $\begin{array}{l}\text { Existe uma deficiência em recursos } \\
\text { humanos e materiais, além de estrutura } \\
\text { física que dificulta as atividades de } \\
\text { promoção, proteção e reabilitação da } \\
\text { saúde. Apenas as atividades de natureza } \\
\text { curativa e as campanhas de imunização } \\
\text { sem sendo realizadas pela ESF com } \\
\text { eficiência. }\end{array}$ \\
\hline $\begin{array}{l}\text { 6.SOUSA, } \\
\text { G.C; } \\
\text { CABRAL, } \\
\text { K.D.S; } \\
\text { SALGUEIRO- } \\
\text { LEITE, C.D.B } \\
(2018)\end{array}$ & $\begin{array}{l}\text { Analisar na literatura, } \\
\text { as ações de } \\
\text { Educação r } \\
\text { Promoção à Saúde } \\
\text { da Mulher praticada } \\
\text { pela enfermagem, } \\
\text { para mulheres } \\
\text { privadas r de } \\
\text { liberdade. }\end{array}$ & $\begin{array}{l}\text { Enfocam a vulnerabilidade biopsicossocial } \\
\text { das mulheres potencializada na situação } \\
\text { prisional, maximizando os déficits de } \\
\text { ações em saúde, sendo o papel da } \\
\text { enfermagem importante no que tange às } \\
\text { atribuições da profissão, garantindo os } \\
\text { direitos dessa população }\end{array}$ \\
\hline $\begin{array}{l}\text { 7.SOARES } \\
\text { FILHO, } \\
\text { M.M.S; } \\
\text { BUENO, } \\
\text { P.M.M.G } \\
(2016)\end{array}$ & $\begin{array}{l}\text { Analisar - na direção } \\
\text { da garantia do direito } \\
\text { humano à saúde - as } \\
\text { pesquisas mais } \\
\text { recentes sobre o } \\
\text { perfil da população } \\
\text { prisional brasileira e } \\
\text { a sua demografia, } \\
\text { além das leis e } \\
\text { normas existentes. }\end{array}$ & $\begin{array}{l}\text { A superlotação, as condições de vida e a } \\
\text { assistência à saúde mostram claramente a } \\
\text { falência do sistema prisional Brasileiro, } \\
\text { fato que implica na necessidade de } \\
\text { mudança urgente desse panorama afim de } \\
\text { que a legislação seja seguida e os direitos } \\
\text { assegurados. }\end{array}$ \\
\hline $\begin{array}{l}\text { 8.MARTINS, } \\
\text { E.L.C et al } \\
(2014)\end{array}$ & $\begin{array}{l}\text { Analisar a efetivação } \\
\text { do direito à saúde } \\
\text { das pessoas em } \\
\text { privação } \\
\text { liberdade. }\end{array}$ & $\begin{array}{l}\text { Constata-se a não realização do direito à } \\
\text { saúde tanto para as pessoas presas como } \\
\text { para os profissionais que atuam no } \\
\text { presídio }\end{array}$ \\
\hline $\begin{array}{l}\text { 9. SANTOS, } \\
\text { R.P et al. } \\
(2019)\end{array}$ & $\begin{array}{l}\text { Descrever a } \\
\text { ocorrência de } \\
\text { doenças } \\
\text { infectocontagiosas } \\
\text { em pessoas privadas } \\
\text { de liberdade no } \\
\text { sistema prisional. }\end{array}$ & $\begin{array}{l}\text { Classificam os apenados como público } \\
\text { vulnerável a doenças infecciosa, listando a } \\
\text { sífilis e tuberculose com } 8 \% \text {; escabiose } \\
\text { com } 7,1 \% \text {; micoses com } 6,2 \% \text {; HIV com } \\
4,4 \% \text {; gonorreia com } 3,5 \% \text {; herpes genital, } \\
\text { HPV, meningite e hepatite B com } 1,7 \% \text {; e } \\
\text { hepatites A e C com } 0,8 \% \text {. }\end{array}$ \\
\hline
\end{tabular}

Fonte: Dados da Pesquisa, 2019. 
Com o objetivo de analisar a implantação e efetividade do PNSSP em um município do Rio Grande do Norte, Henrique Júnior et al. (2013) realizaram um estudo em pesquisa direta, onde constataram uma grande deficiência em termos de conhecimento do plano, além de observação de um estado de grande precariedade do serviço e das ações de saúde à população privada de liberdade. A proposta de oferta de serviços visando à promoção da saúde não é eficaz, sendo substituída apenas por ações curativas e de urgência.

Apesar de todos os estados e o distrito federal estarem hoje habilitados no PNSSP, representam apenas $30 \%$ de cobertura em termos numéricos, pois, embora a elegibilidade seja total, esta cobertura irá depender da velocidade de habilitação e implantação dos serviços e equipes de saúde no sistema penitenciário pelos estados nas unidades prisionais (BRASIL, 2013).

Para Freitas et al (2016), diversas falhas podem interferir para que as premissas do PNSSP sejam ineficientes, e entre elas, estão o aumento vertiginoso de diversas doenças decorrentes da superpopulação e das condições de encarceramento, a redução do número de profissionais de saúde que atuam no sistema prisional, a falta de implantação de um plano operativo estadual que assegure o acesso à saúde desta população, a ausência de uma política pública de saúde e de saúde mental específica, e a dificuldade para implementar o controle social nesse meio.

A superlotação é abordada por diversos autores como fator dificultante para as questões de saúde nos presídios. Para Cordeiro et al. (2018), o aglomerado de pessoas e a falta de condições básicas de higiene estão intimamente ligados ao aparecimento de doenças, entre elas infecciosas e notificáveis. Os autores concluíram que o HIV e Tuberculose estão entre as doenças infecciosas mais notificadas, porém mostram números alarmantes de $77 \%$ da população carcerária sem histórico de notificações, o que leva a pensar em casos de doenças não notificadas pelo sistema.

Corroborando os autores acima citados, Brasil (2016) aponta um índice superior a 28 vezes para tuberculose quando comparada a população privada de liberdade aos demais pacientes. Este índice, somado à demora na identificação dos portadores da doença, à dificuldade no isolamento daqueles portadores 
diagnosticados, à alta rotatividade de detentos, celas pequenas e pouco ventiladas, e ao tempo de encarceramento, contribui para a alta incidência de muitas doenças entre pessoas privadas de liberdade, embora sub notificadas (OLIVEIRA, 2016).

Para Santos et al. (2019), a vulnerabilidade das pessoas privadas de liberdade é comprovada pela alta prevalência de doenças infecciosas. Em seu estudo, os autores elencaram a sífilis e tuberculose como sendo as doenças com maior prevalência entre os apenados.

Além das doenças infecciosas, doenças crônicas como Diabetes, hipertensão possuem alta prevalência entre os apenados que possuem também alto percentual de uso de drogas lícitas e ilícitas. Segundo Alves et al. (2017), a maioria da população prisional é composta por adultos jovens de 19 a 29 anos que possuem boa capacidade de recuperação quando tratados adequadamente, porém admitindo problema em diagnóstico de tratamento de doenças crônicas e infecciosas.

Apesar de a população carcerária no Brasil ser majoritariamente do sexo masculino, informações colhidas através do Departamento Penitenciário Nacional (DEPEN) mostram um crescimento maior na população carcerária feminina, chegando a números de 256\% em 2012 (BRASIL, 2013). A vulnerabilidade da mulher no sistema prisional é abordada por Souza; Cabral; Leite-Salgueiro (2018), quando enfocam a decadência de serviços de saúde oferecidos a essas mulheres, assim como no sexo masculino, estando ainda em desvantagem devido à necessidade de cuidados de saúde da mulher e da gestante, estes também considerados insatisfatórios.

Para Valim; Diabem. Hossne (2018), toda essa problemática inicia-se desde o momento de entrada dos presos no sistema penitenciário, pois inexiste uma avaliação inicial de saúde que é proposta pelo PNSSP como o protocolo mínimo. Essa dificuldade acarreta um controle ineficaz de patologias existente no momento da entrada, assim como das patologias que porventura sejam adquiridas no decorrer do tempo.

Objetivando avaliar as ações que a estratégia de saúde da família (ESF) desenvolve com a população carcerária sobre sua área de abrangência, Costa et al. (2014) evidenciam uma grande deficiência nestas ações, relacionadas à falta de estrutura física e de recursos humanos e materiais, havendo uma necessidade 
urgente de investimentos para que as ações deixem de ser apenas curativas e de imunização.

Para Soares Filho, Bueno (2016), a população encarcerada no Brasil vive em péssimas condições de saúde, estando abaixo da linha de dignidade mínima, não sendo assegurados os direitos constitucionais previstos, chegando a ser objeto de intervenção devido à, entre outros grandes problemas, prevalência consideravelmente elevada de doenças transmissíveis ou não, fato que afeta diretamente a vida das pessoas e dificulta a probabilidade de ressocialização. Segundo os autores, o sistema penitenciário Brasileiro encontra-se em falência pelos péssimos serviços ofertados.

A realidade acima descrita é percebida também pelos sujeitos de todo este processo. Em seu estudo realizado com apenados e profissionais de saúde, Martin et al. (2014) revelam o descaso do estado com os detentos, negando o direito à saúde garantido legalmente, fato que se estende também aos profissionais que trabalham no sistema por não ter apoio nem clínico, tampouco psicológico.

\section{CONSIDERAÇÕES FINAIS}

De acordo com as informações coletadas dentro da amostragem selecionada, pode-se perceber uma unanimidade nos autores quando se fala do sucateamento das unidades prisionais Brasileiras e com isso de todos os serviços que deixam de ser ofertados ao cidadão que está privado de liberdade.

A saúde, como direito do cidadão e dever do Estado, é afirmada na legislação em vários momentos, inclusive em planos e programas específicos para o sistema prisional, porém sua aplicabilidade está longe de ser considerada ideal.

A assistência universal e integral, baseada na promoção, proteção e reabilitação da saúde, é apenas burocrática, restando aos reclusos ações curativas e pontuais longe dos preceitos de humanização. 
Em suma, vê-se a necessidade de investimentos estruturais e em recursos humanos como forma demudar essa realidade e oferecer condições mínimas de saúde às pessoas privadas de liberdade.

\section{REFERÊNCIAS BIBLIOGRÁFICAS}

ALVES, Jeorgia Pereira et al. Perfil Epidemiológico de Pessoas Privadas de Liberdade. Rev enferm UFPE on line., Recife. v. 11, supl. 10, p. 4036-4044, 2017. Disponível em: $<$ https://periodicos.ufpe.br/revistas/revistaenfermagem/article/view/231163/25123>. Acesso em 09 maio 2019. doi: http://dx.doi.org/10.5205/reuol.10712-95194-3-SM.1110sup201705.

BARBOSA, Mayara Lima et al. Atenção básica à saúde de apenados no sistema penitenciário: subsídios para a atuação da enfermagem. Esc Anna Nery. v. 18, n. 4, p. 586-592, 2014. Disponivel em: <http://www.scielo.br/pdf/ean/v18n4/1414-8145-ean-18-04-0586.pdf>. Acesso em 13 maio 2019. doi: http://dx.doi.org/10.5935/1414-8145.201400083.

BRASIL. Ministério da Saúde. Secretaria de Atenção à Saúde. Departamento de Ações Programáticas Estratégicas. Área Técnica de Saúde no Sistema Penitenciário. Plano Nacional de Saúde no Sistema Penitenciário. Tiragem: $1^{a}$ edição - 2004 - 7.000 exemplares. Disponível em:<http://bvsms.saude.gov.br/bvs/publicacoes/cartilha_pnssp.pdf >. Acesso em 09 maio 2019.

BRASIL. Ministério da Saúde. Tuberculose: populações vulneráveis [Internet]. 2016. Disponível em:<http://portalms.saude.gov.br/saude-de-a-z/tuberculose/populacoesvulneraveis>. Acesso em 08 maio 2019.

BRASIL. Ministério da Saúde. Sistema Cadastro Nacional de Estabelecimentos de Saúde. [Online]. 2013. Disponível em:<http://cnes.datasus.gov.br/>. Acesso em 10 maio 2019.

CAPEZ, Fernando. Direito penal. Disponível em: <http://lelivros.win/book/download-cursodedireito-penal-vol-1-parte-geral-fernando-capez-em-epub-mobi-e-pdf/>. Acesso em: 10 maio 2019.

CORDEIRO, Eliana Lessa et al. Perfil epidemiológico dos detentos: patologias notificáveis. Av Enferm. v. $36, \quad$ n. 2, p. 170-178, 2018. Disponível em:<http://www.scielo.org.co/scielo.php?script=sci_arttext\&pid=S0121-45002018000200170>. Acesso em 09 maio 2019. doi: http://dx.doi.org/10.15446/av.enferm.v36n2.68705.

COSTA, Gabriela Maria Cavalcnati et al. A saúde dos detentos sob a responsabilidade das equipes de saúde da família: Realidade e Possibilidades. Rev. APS. v. 17, n. 1, p. 76-84, 2014. Disponível em:<http://periodicos.ufj.br/index.php/aps/article/view/15308>. Acesso em 08 mai 2019.

FREITAS, Rosane Souza et al. Política Nacional e Ação Integral a Pessoas Privadas de Liberdade: Uma análise do seu processo de formulação e implantação. R. Pol. Públ., São Luís, v. $20, \quad \mathrm{n} \quad 1, \quad$ p.171-184, 2016.2 Disponível em: <http://www.periodicoseletronicos.ufma.br/index.php/rppublica/article/view/5043/3093>. Acesso em 11 maio 2019.

HENRIQUE JUNIOR, João Wellton de Azevedo. O cuidado na Atenção Primária a Saúde da população carcerária masculina no município de Caraúbas/RN. Revista Baiana de Saúde Pública. v.37, n.2, p.394-406, 2013. Disponível em:<http://files.bvs.br/upload/S/01000233/2013/v37n2/a4449.pdf>. Acesso em 12 maio 2019. 
LEARN, Helena Salgueiro et al. Saúde no cárcere: análise das políticas sociais de saúde voltadas à população prisional brasileira. Physis Revista de Saúde Coletiva, Rio de Janeiro. v. 25, n. 3, p. 905-924, 2015. Disponível em:<http://www.scielo.br/pdf/physis/v25n3/0103-7331physis-25-03-00905.pdf>. Acesso em 13 maio 2019. doi: http://dx.doi.org/10.1590/S010373312015000300012 .

MARTINS, Élida Lúcia Carvalho et al. O contraditório direito à saúde de pessoas em privação de liberdade: o caso de uma unidade prisional de Minas Gerais. Saúde soc. v. 23, n. 4, p. 1222-1234, 2014. ISSN 0104-1290. Disponível em:<http://www.scielo.br/scielo.php?pid=S010412902014000401222\&script=sci_abstract\&tlng=en>. Acesso em 10 maio 2019 . doi: http://dx.doi.org/10.1590/S0104-12902014000400009.

OLIVEIRA, Elaine Cristine Santos Serejo de et al. Perfil epidemiológico dos internos de uma central de custódia de presos de justiça. Rev enferm UFPE online. v. 10, n. 9, p. 3377-3383, 2016. Disponível em: <https://periodicos.ufpe.br/revistas/revistaenfermagem/>. Acesso em 11 maio 2019.

POLIT, Denise F. et al. Fundamentos de pesquisa em enfermagem: métodos, avaliação e utilização. 5. ed. Porto Alegre (RS): Artmed, 2004.

LOPES, Roberta Lopes et al. Ocorrência de doenças infectocontagiosas em pessoas privadas de liberdade no sistema prisional. Interfaces Científicas, Aracaju. v. 7, n. 2, p. 53-60, 2019. Disponível em: <https://periodicos.set.edu.br/index.php/saude/article/view/5962>. Acesso em 12 maio 2019. doi: http://dx.doi.org/10.17564/2316-3798.2019v7n2p\%25p.

SILVA, M. Saúde penitenciária no Brasil: Plano e política. Brasília: Verbena, 2015. 117p.

SOARES, Cassia Baldini et al. Revisão integrativa: conceitos e métodos utilizados na enfermagem. RevEscEnferm USP. v. 48, n. 2, p. 335-345, 2014. Disponível em: <http://www.scielo.br/pdf/reeusp/v48n2/pt_0080-6234-reeusp-48-02-335.pdf>. Acesso em 12 maio 2019. doi: http://dx.doi.org/10.1590/S0080-6234201400002000020.

SOARES FILHO, Marden Marques; BUENO, Paula Michele Martins Gomes. Demografia, vulnerabilidades e direito à saúde da população prisional brasileira. Ciência \& Saúde Coletiva. v. 21, n. 7, p. 1999-2010, 2016. Disponível em: <https://www.scielosp.org/pdf/csc/2016.v21n7/1999-2010/pt>. Acesso em: 09 maio 2019. doi: http://dx.doi.org/10.1590/1413-81232015217.24102015.

SOUSA, Marcela Tavares de; SILVA, Michelly Dias da; CARVALHO, Rachel de. Revisão integrativa: o que é e como fazer? Einstein. v. 8, n. (pt. 1), p. 102-106, 2010. Disponível em: <http://www.scielo.br/pdf/eins/v8n1/pt_1679-4508-eins-8-1-0102>. Acesso em 11 maio 2019. doi: http://dx.doi.org/10.1590/s1679-45082010rw1134.

SOUZA, Geovanna Camelo; CABRAL, Karian Dyanna Salvador; SALGUEIRO, Cláudia Daniele Barros Leite. Reflexões sobre a Assistência em enfermagem à mulher Encarcerada: Uma Revisão Integrativa. Arq. Ciênc. Saúde UNIPAR, Umuarama. v. 22, n. 1, p. 55-62, 2018. Disponível em: <http://www.revistas.unipar.br/index.php/saude/article/view/6240/3563>. Acesso em 07 maio 2019. doi: https://doi.org/10.25110/arqsaude.v22i1.2018.6240.

VALIM, Edna Maria Alves; DAIBEM, Ana Maria Lombardi; HOSSNE, William Saad. Atenção à saúde de pessoas privadas de liberdade. Rev. bioét. v. 26, n. 2, p. 282-290, 2018. Disponível em: <http://www.scielo.br/pdf/bioet/v26n2/1983-8042-bioet-26-02-0282.pdf>. Acesso em 10 maio 2019. doi: http://dx.doi.org/10.1590/1983-80422018262249. 